\title{
Flexural Behavior of Bamboo Reinforced Concrete Beam with Steel Stirrups
}

\author{
K.Ramakrishnan, S. Aravind, V. Ananthababu
}

\begin{abstract}
The flexural behavior of concrete beams reinforced with bamboo was studied experimentally. Bamboo was used as the main reinforcement with different bonding materials in place of steel. A nominal mix of M20 grade concrete was adopted for the beam design. The Bamboo surface was treated with common binding materials like Araldite and Bitumen. Araldite and Bitumen are good binding materials used to connect materials like steel, carbon and many different materials. Two specimens were casted with bitumen coating, two specimens were coated with araldite, two specimens were casted without any binder coating and a specimen was casted using normal steel reinforcement. Beams were casted with bamboo reinforcement and cured for 28 days. Deflection and flexural behavior of the beams were monitored. The test results imply that araldite coating in concrete beams with bamboo reinforcement increased the flexural strength to that of bamboo reinforced concrete using bitumen which is lesser strength to that of steel reinforced concrete beam.
\end{abstract}

Keywords : flexural, reinforcement, beam, strength, deflection, bamboo.

\section{INTRODUCTION}

Bamboo is identified as a biodegradable, energy efficient and renewable natural resource which can be used as a building material that is sustainable and can also be used for structural purposes. Its strength to weight ratio is more when compared with conventional materials like steel, concrete, etc. At present, bamboo is scarcely used as a building material because of its dimensional instability due to moisture, bonding, difficult connections due to its irregular shape, lack of official design codes and standards. The tensile strength of bamboo is higher than many construction materials and this makes bamboo as a very good alternative to steel in applications involving tensile loading. This is because the ratio of tensile strength to specific weight of bamboo is six times that of steel. The manufacturing process of steel involves high energy consumption and also leads to pollution which can be avoided by using locally available bamboo as a structural element in the construction industry. Bamboo has high water absorption and it create adverse effects for the durability of the structure. Coating with layers of araldite or bitumen helps to reduce this problem considerably while

Revised Manuscript Received on December 05, 2019.

* Correspondence Author

Dr. K. Ramakrishnan*, School of Civil Engineering , SASTRA Deemed to be University, Thanjavur, India. Email: ramakrishnan@civil.sastra.edu.

S. Aravind, School of Civil Engineering, SASTRA Deemed to be University, Thanjavur, India. Email: aravinds@sastra.ac.in

V. Ananthababu, Former M.Tech. student, School of Civil Engineering SASTRA Deemed to be University, Thanjavur, India. Email: babumithran@gmail.com improving the strength characteristics than that of uncoated bamboo reinforced elements. Chemical coating over entire concrete section and addition of suitable mineral admixtures in concrete to reduce the permeability are other viable options to prevent fungal and termite attack on bamboo and improve the durability of the structure. The minimum reinforcement required for bamboo reinforced concrete is about $3.5 \%$ for adequate crack control.

Ghavami(1995) made a study of physical and mechanical properties of seven different types of bamboo and inferred that the ultimate applied load of the concrete beam reinforced with bamboo was five times higher than the concrete beams without bamboo reinforcement. The addition of bamboo by $3 \%$ was found to be optimal. The bamboo-concrete bonding was improved by $90 \%$ by the negrolin sand wire treatment. Shigeyasu et al.(2001) made a study on fracture toughness of bamboo culms and nodes and concluded that the fracture toughness depends on the volume fraction of fibres. Fracture toughness of the bamboo culm was higher on the outer surface layer and decreases towards the inner surface. Khosrow (2005) studied the bamboo microstructure to identify its potential as a functionally gradient material and came to a conclusion that bamboo can substitute steel satisfactorily and also contribute to sustainable development and many building construction shall be carried out with bamboo as a structural member. Suresh et al.(2008) studied about the replacement of concrete and steel with bamboo which leads to sustainable construction practice. Hongyan et al.(2009) studied about the moisture absorption property of bamboo strips and its effect on the shear strength (IFSS) of bamboo/vinyl ester composite at interfacial layer. Yan et al.(2010) studied comprehensively about developing and using bamboo structures for buildings and bridges. It was found that the bamboo girders with lamination have acceptable stiffness and load carrying capacity. The stiffness and capacity of the bamboo girders can be further enhanced by the use of carbon fiber-reinforced plastics. Mahzuz et al. (2011) studied about the strength and durability properties of bamboo as a construction material and concluded that bamboo could be used for low cost housing applications. Terai et al. (2011) studied about the seismic resistance offered by bamboo as a masonry construction material. He observed that the cracking patterns in bamboo reinforced concrete beams was similar to the RCC beams. Harish et al. (2012) studied the physical and mechanical properties of bamboo and concluded that the compressive and tensile strength behavior of bamboo is similar to that of steel. The bond strength of bamboo is low while the water absorption is high when compared to steel and these can be improved by providing suitable coatings. Siddhpura et al (2013) studied about the flexural behavior of bamboo in its use as a structural element.

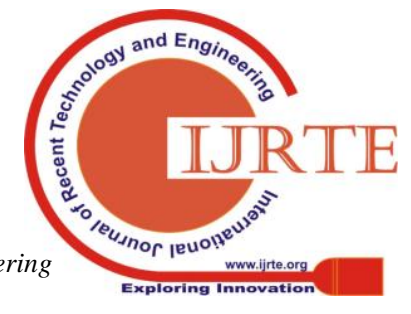




\section{EXPERIMENTAL INVESTIGATION}

It comprises of casting of beams for flexural test under three point loading test. The materials used, mix proportions and the test methods are described in the following sections.

\section{A. Materials used}

1) Cement - 53 grade OPC conforming to IS: 12269 was used. The relative density of cement was determined to be 3.15 by experimentation.

2) Fine aggregate - River sand that is locally available and that passes through $4.75 \mathrm{~mm}$ sieve was used. The relative density was determined to be 2.65 .

3) Coarse aggregate- Coarse aggregates which are retained in $4.75 \mathrm{~mm}$ sieve were used. The relative density was determined to be 2.75 .

4) Bamboo- Bamboo is used as a main reinforcement in the present study; $18 \mathrm{~mm}$ diameter bamboo is chosen for experimental investigation.

5) Water - Fresh locally available water was used for mixing and curing of polypropylene beams.

\section{6) Bonding Materials}

a) Araldite

b) Bitumen

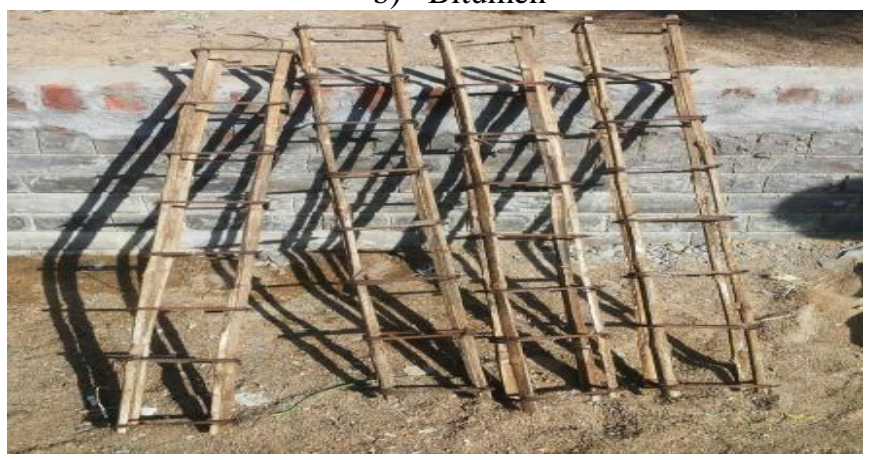

Fig. 1 View of bamboo reinforced beams with steel stirrups

\section{B. Casting}

A concrete mixture with a ratio of 1:1.5:3 is used for casting the beams. Two specimens were casted with bitumen coated bamboo reinforcement, two specimens were casted with araldite coated bamboo reinforcement, two specimens were casted with bamboo reinforcement without any binder coating and one specimen was casted using normal steel reinforcement. The size of the beams were $1200 \times 100 \times 150$ $\mathrm{mm}$ with an effective span of $1000 \mathrm{~mm}$. Cover of $25 \mathrm{~mm}$ was used with a reinforcement of 4 nos of $18 \mathrm{~mm} \varnothing$ bamboo bars at bottom and top, $6 \mathrm{~mm} \varnothing$ stirrups are provided at $150 \mathrm{~mm}$ spacing. The coated bamboo reinforcements were provided with sand top to ensure better grip. The percentage of reinforcement provided is $6.78 \%$ which is more than the minimum reinforcement required. Demolding is done after a day and the curing of the specimens were done for 28 days.

\section{Testing}

Flexural strength test - The test was conducted on Universal Testing Machine. The test setup in Figure 2 shows the load transfer mechanism as a two point symmetrical loading through rigid steel girder. The span of the beam was $1000 \mathrm{~mm}$ between the supports, thus the flexure span was the middle span of length $333.3 \mathrm{~mm}$. The crack patterns were drawn on the beam directly. The test was conducted till the ultimate load was obtained. The size of the beam adopted for testing was $100 \times 150 \times 1200 \mathrm{~mm}$.

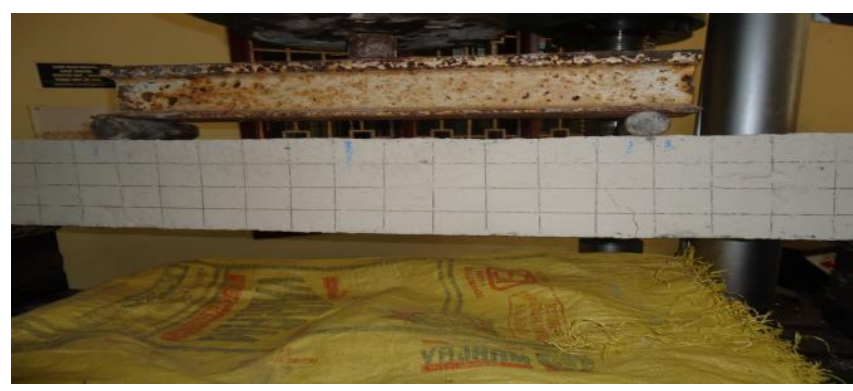

Fig. 2 Test setup of three point loading

\section{RESULTS AND DISCUSSIONS}

\section{A. Flexural strength test}

One specimen of concrete beam reinforced with steel (RCC), two specimens with uncoated bamboo reinforced sections, two specimens with bamboo reinforced section coated with araldite and two specimens with bamboo reinforced section coated with bitumen were tested for flexure. Beam size of 100x150x1200 was adopted for all the sections. The maximum flexural strength obtained from the experiment is tabulated in Table 1 .

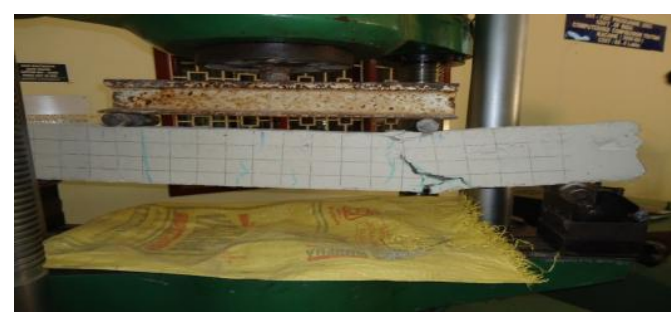

Fig. 3 Deflected view of bamboo beams

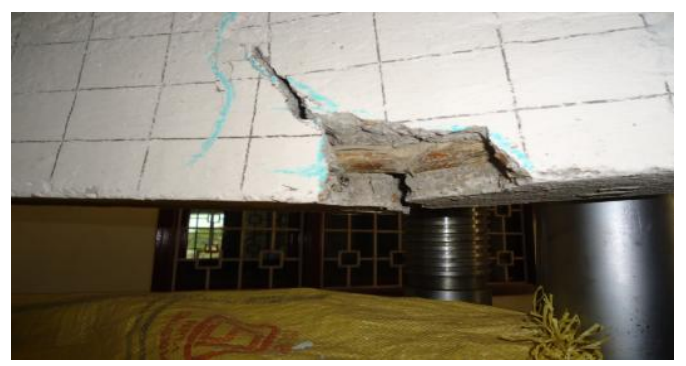

Fig. 4 Cracking pattern of bamboo beams

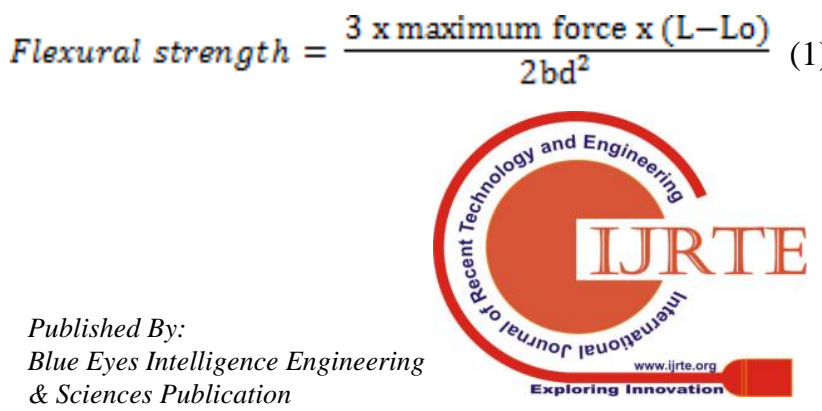


TABLE I. FLEXURAL STRENGTH OF BAMBOO BEAMS

\begin{tabular}{|c|c|c|}
\hline Materials & Ultimate load $(\mathrm{kN})$ & $\begin{array}{c}\text { Flexural strength } \\
\left(\mathrm{N} / \mathbf{m m}^{2}\right)\end{array}$ \\
\hline $\mathrm{RCC}$ & 19.65 & 2.183 \\
\hline BRCB-1 & 9.73 & 1.081 \\
\hline BRCB-2 & 11.09 & 1.232 \\
\hline $\begin{array}{l}\text { BRCB- } \\
\text { BITUMEN } 1\end{array}$ & 11.81 & 1.312 \\
\hline $\begin{array}{l}\text { BRCB- } \\
\text { BITUMEN } 2\end{array}$ & 13.17 & 1.463 \\
\hline $\begin{array}{l}\text { BRCB- } \\
\text { ARALDITE } 1\end{array}$ & 14.43 & 1.603 \\
\hline $\begin{array}{l}\text { BRCB- } \\
\text { ARALDITE } 2\end{array}$ & 14.96 & 1.662 \\
\hline 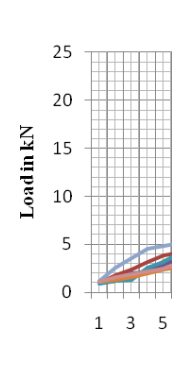 & $\begin{array}{c}9111315171921232 \\
\text { Displacement in mm }\end{array}$ & $\begin{array}{l}\text { RCC } \\
\text { RRCB-1 } \\
\text { BRCB-2 } \\
\text { BRCB-BITUMEN } 1 \\
\text { BRCB-BITUMEN } 2 \\
\text { BRCB-ARALDITE } 1 \\
\text { BRCB-ARALDITE } 2\end{array}$ \\
\hline
\end{tabular}

Fig. 5 Load vs Displacement curve

\section{B. Discussion}

The test result indicates that the flexural strength of bamboo reinforced concrete beam section with araldite and bitumen coating were $76 \%$ and $67 \%$ of the flexural strength of the concrete beam section cast with steel reinforcement while the flexural strength of bamboo reinforced beam section without any coating was observed to be $56 \%$ of the RCC section. The araldite and bitumen coating of bamboo surface decreases the water absorption thus improving the strength and durability characteristics of the member. The usage of locally available materials like bamboo helps reduce steel consumption thus lowering the energy impact and environmental pollution considerably.

\section{CONCLUSION}

Based on the experimental study on bamboo reinforcement in concrete, the following conclusions were drawn.

1) Flexural strength of bamboo reinforced concrete using araldite and bitumen are $76 \%$ and $67 \%$ to that of RCC section whereas the flexural strength of bamboo reinforced concrete is $56 \%$ to that of the RCC section.

2) The higher flexural strength of araldite coated bamboo reinforced concrete beam can be attributed to better bonding between bamboo and concrete.

3) Bamboo reinforced concrete beam without any coating has the lowest flexural strength and the beam failed predominantly in shear.

4) Both flexural and shear cracks were observed in both araldite and bitumen coated bamboo reinforced concrete beams.

5) Araldite coating of bamboo provided better bonding characteristics than bitumen coating.

6) Bamboo reinforced concrete can be used in relatively dry environments and where alternate drying and wetting of concrete is not predominant.
7) Bamboo reinforced concrete can not be used where there is more moisture content in air or the environment contains aggressive chemicals like sulphates and chlorides that pose a threat to the durability of concrete.

\section{REFERENCE}

1. Dr. Patel Pratima ,Patel Jaymin, Magdallawala Sunny, MaiwalaAdit, Gajera Vivek, "Design of bamboo reinforced concrete water tank resting over firm ground", International Journal Of Engineering, Business and Enterprise Applications, vol. 4(2), pp. 113-117, 2013.

2. K. Ghavami, "Ultimate load behavior of bamboo reinforced lightweight concrete beams", Cement \& Concrete composites, vol. 17, pp. 281-288, 1995.

3. H. M. A. Mahzuz, Mushtaq Ahmed, Md. Ashrafuzzaman, Rejaul Karim and Raju Ahmed, "Performance evaluation of bamboo with mortar and concrete", Journal of Engineering and Technology Research, vol. 3(12), pp. 342-350, 2011.

4. Harish Sakaray, N.V. Vamsi Krishna Togati and I.V Ramana Reddy, "Investigation on properties of bamboo as reinforcing material in concrete", International Journal of Engineering Research and Applications, vol. 02(01), pp. 077-083, 2012.

5. Hongyan Chen, Menghe Miao, Xin Ding, "Influence of moisture absorption on the interfacial strength of bamboo/vinyl ester composites", Journal on Composites Part A, vol. 40, pp. 2013-2019, 2009 .

6. Khosrow Ghavami, "Bamboo as reinforcement in structural concrete elements", Cement \& Concrete composites, vol. 27, pp. 637-649, 2005.

7. Masakazu Terai, Koichi Minami, "Fracture behavior and mechanical properties of bamboo reinforced concrete members", Journal on Procedia Engineering, vol. 10, pp. 2967-2972, 2011.

8. Shigeyasu Amada, Sun Untao, "Fracture properties of bamboo", Journal on composites part b, vol. 32(01), pp. 451-459, 2001.

9. B. Siddhpuraa, Nirav, B. Deep Shaha, V. Jai Kapadiaa, S. Chetan Agrawala and K. JigarSevaliaa, "Experimental study on flexura element using bamboo as reinforcement", International Journal of Current Engineering and Technology, vol. 03(02), pp. 476-483, 2013.

10. Suresh Bhalla, Supratic Gupta, PuttaguntaSudhakar, Rupali Suresh, "Bamboo as green alternative to concrete and steel for modern structures, Journal of Environmental Research and Development, vol. 03(02), 2008.

11. Yan Xiao, Quan Zhou, Bo Shan, "Design and construction of modern bamboo bridges", Journal of Bridge Engineering, ASCE, pp. 533, 2010.

12. Yushun Li, Huangying Shen, WeiShan, Tianshi Han, "Flexural behavior of lightweight bamboo-steel composite slabs", Thin-walled structures, vol. 53, pp. 83-90, 2012.

13. ZongjinLi,Chun-Pong Liu, and Tongxi Yu, "Laminate of reformed bamboo and extruded fiber-reinforced cementitious plate", Journal of Materials in Civil Engineering, pp. 359, 2002.

14. Hector Archila, Sebastian Kaminski, David Trujillo, Edwin Zea Escamilla and Kent A. Harries, "Bamboo reinforced concrete : A critical review", Materials and Structures, vol. 51(102), 2018.

\section{AUTHORS PROFILE}

Dr. K. Ramakrishnan School of Civil Engineering, SASTRA Deemed to be University, Thanjavur, India.

S. Aravind School of Civil Engineering, SASTRA Deemed to be University, Thanjavur, India.

V. Ananthababu Former M.Tech. student, School of Civil Engineering, SASTRA Deemed to be University, Thanjavur, India. 